\title{
Efeito da suplementação com cultura de levedura na fermentação ruminal de bovinos de corte ${ }^{1}$
}

\section{Carlos Borges Assumpção Gattass², Maria da Graça Morais ${ }^{3}$, Urbano Gomes Pinto de Abreu, Gumercindo Loriano Franco ${ }^{3}$, Joice Stein ${ }^{3}$, Beatriz Lempp ${ }^{3}$}

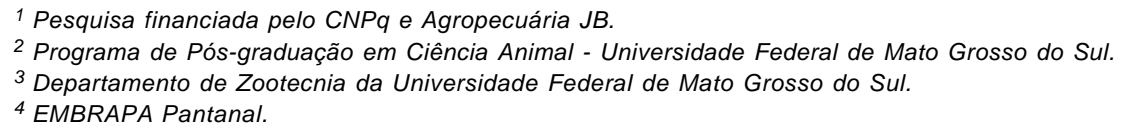

RESUMO - Este trabalho foi conduzido para avaliar os efeitos da inclusão de cultura de levedura (Saccharomyces cerevisiae cepa 1026) sobre os parâmetros da fermentação ruminal de bovinos de corte. Foram utilizados dez novilhos $1 / 2$ Red Angus 1/2 Nelore, canulados no rúmen, mantidos em baias individuais alimentados com $50 \%$ de volumoso à base de silagem de sorgo e $50 \%$ de concentrado contendo casca de soja peletizada, sorgo em grão moído, uréia e núcleo protéico mineral (\%MS). Utilizou-se o delineamento inteiramente casualizado, com dois tratamentos, que consistiram da inclusão ou não de Saccharomyces cerevisiae $(1 \mathrm{~g} / 100 \mathrm{~kg} \mathrm{PC})$ à dieta em duas das quatro refeições diárias. $\mathrm{O} \mathrm{pH}$, as concentrações ruminais de nitrogênio amoniacal $\left(\mathrm{N}-\mathrm{NH}_{3}\right.$ ), acetato, propionato, butirato e ácidos graxos voláteis (AGV) totais e a relação acetato:propionato não foram influenciados pela suplementação com cultura de levedura. Houve interação entre os tempos de amostragem e os tratamentos para pH e concentrações molares de acetato e propionato. $\mathrm{O}$ pH, as concentrações ruminais de acetato, propionato e AGV totais e a relação acetato:propionato aumentaram de forma quadrática de acordo com os tempos de coleta. Em bovinos de corte alimentados com dietas com relação volumoso:concentrado 50:50, a suplementação com cultura de levedura não influencia os parâmetros da fermentação ruminal.

Palavras-chave: ácidos graxos voláteis, nitrogênio amoniacal, novilhos, pH

\section{Effect of yeast culture supplementation on ruminal fermentation of beef cattle}

\begin{abstract}
This study evaluated the effects of the inclusion of a yeast culture (Saccharomyces cerevisiae 1026) on the parameters of ruminal fermentation of beef cattle. Ten rumen fistulated 1/2 Red Angus 1/2 Nellore steers confined in individual pens were fed a diet containing $50 \%$ sorghum silage and $50 \%$ concentrate $(\% \mathrm{DM})$ containing peleted soybean hulls, sorghum grain, urea and mineralproteic premix. A completely randomized design was used to compare diets with or without Saccharomyces cerevisiae $(1 \mathrm{~g} / 100 \mathrm{~kg}$ of live weight) on two of the four daily meal. Ruminal $\mathrm{pH}$, ruminal concentrations of ammoniacal nitrogen $\left(\mathrm{N}-\mathrm{NH}_{3}\right)$, acetate, propionate, butyrate, total volatile fatty acid (VFA) and acetate:propionate ratio values were not influenced by the supplementation of yeast culture. There were interaction between sampling time and treatments for $\mathrm{pH}$, and molar concentrations of acetate and propionate. Ruminal $\mathrm{pH}$, ruminal concentrations of acetate, propionate, total VFA and acetate:propionate ratio showed a quadratic response related to collection time. In diets with 50:50 forage to concentrate ratio, the supplementation of yeast culture did not influence the ruminal fermentative parameters.
\end{abstract}

Key Words: ammoniacal nitrogen, pH, steers, volatile fatty acid

\section{Introdução}

A União Européia (UE) baniu, desde janeiro de 2006, o uso de quaisquer antibióticos usados como promotores de crescimento nas rações. Essa restrição se estendeu aos países exportadores de carne para a União Européia. Essas medidas têm contribuído para intensificar a procura por aditivos alternativos que satisfaçam às exigências do mercado. Entre os aditivos alternativos existentes no mercado, destacam-se as culturas de leveduras, que atuam como probiótico e possuem características que atendem às exigências internacionais dos maiores importadores de carne bovina brasileira.

Segundo Martin \& Nisbet (1992), as culturas de leveduras podem atuar modificando a fermentação ruminal basicamente de duas formas: fornecendo fatores estimulatórios para as bactérias do rúmen e absorvendo o oxigênio que entra no ambiente ruminal. Os principais 
fatores estimulatórios parecem ser os ácidos dicarboxílicos fornecidos pelas culturas de leveduras, particularmente o ácido málico, que podem favorecer o crescimento e a atividade das bactérias utilizadoras de ácido lático e prevenir flutuações perigosas do $\mathrm{pH}$ ruminal.

A grande afinidade das culturas de leveduras por oxigênio melhora as condições ruminais para os microrganismos anaeróbios. Embora o conteúdo ruminal seja essencialmente anaeróbio, pequenas concentrações de oxigênio dissolvido provenientes do alimento e da saliva podem ser encontradas. Assim, segundo Newbold et al. (1996), na presença de cultura de levedura, são estimulados a atividade e o crescimento das bactérias ruminais, principalmente as celulolíticas. Conseqüentemente, a taxa de degradação ruminal e a digestibilidade aparente da matéria seca (MS), especialmente da fibra, podem se elevar. A utilização de amônia, a síntese e o fluxo de proteína microbiana para o duodeno também podem aumentar como conseqüência da maior atividade das bactérias do rúmen. Tudo isso pode contribuir para melhorar o consumo de MS, a eficiência do metabolismo energético e o desempenho animal (Newbold et al., 1996).

Entre os fatores que podem interferir na resposta de bovinos sob suplementação com cultura de levedura, destacam-se o tipo de forrageira, a proporção volumoso: concen trado (Williams et al., 1991; Adams et al., 1995) e o período e o nível de suplementação (Wallace, 1996). Williams et al. (1991), ao fornecerem suplementação de $10 \mathrm{~g}$ de cultura de levedura/animal/dia a novilhos alimentados com 50 ou $100 \%$ de volumoso, base MS, observaram aumento do $\mathrm{pH}$ ruminal 4 horas após o fornecimento de ração com $50 \%$ de concentrado e diminuição significativa da relação acetato:propionato sem alterações na concentração total de ácidos graxos voláteis. Miranda et al. (1996), trabalhando com rações com 27 ou $37 \%$ de fibra em detergente neutro (FDN) (40 ou $60 \%$ de feno de alfafa, base de MS, respectivamente) e fornecimento de $10 \mathrm{~g}$ de cultura de levedura/animal/dia, obtiveram aumento na concentração de propionato, em ambos os níveis de FDN, sem que a concentração total de ácidos graxos voláteis e de nitrogênio amoniacal fosse alterada.

Por outro lado, Dawson et al. (1990), Malcolm \& Kiesling (1990) e Mir \& Mir (1994), trabalhando com rações com maior proporção de volumoso que de concentrado, não encontraram alterações significativas na fermentação ruminal das rações estudadas quando forneceram cultura de levedura. Resultados favoráveis ao uso de levedura (15,0 g/animal/dia) também não foram confirmados por Franco et al. (2004), em novilhos mestiços alimentados com feno de coastcross e sob suplementação com concentrado e cultura de levedura. Esses autores não encontraram diferença na concentração de nitrogênio amoniacal e no pH do líquido ruminal.

Entretanto, Mutsvangwa et al. (1992), durante 28 semanas, forneceram a bezerros com mais de 3 meses de idade dietas ricas em concentrado e observaram aumento nas concentrações de acetato e de ácidos graxos voláteis totais, bem como diminuição de $\mathrm{pH}$, quando forneceram 8 a $10 \mathrm{~g}$ de cultura de levedura/animal/dia.

A inconsistência dos resultados obtidos na literatura relacionada ao uso de cultura de levedura para bovinos de corte torna a decisão difícil, principalmente quando se considera o custo relativamente elevado dos produtos comerciais disponíveis. Este estudo foi conduzido com o objetivo de verificar os efeitos da suplementação de cultura de levedura sobre os parâmetros da fermentação ruminal em bovinos de corte.

\section{Material e Métodos}

Foram utilizados dez novilhos cruzados 1/2 Red Angus $1 / 2$ Nelore, com peso médio inicial de $380 \mathrm{~kg}$ e 24 meses de idade, portadores de cânula permanente no rúmen, distribuídos aleatoriamente em grupo controle e grupo levedura. Os animais foram mantidos em baias individuais cobertas, com piso de concreto e providas de comedouro, bebedouro e água à vontade.

A ração dos animais foi composta de silagem de sorgo como volumoso e uma mistura com casca de soja peletizada, sorgo em grão moído, uréia e núcleo proteicomineral, fornecida narazão 50:50 concentrado:volumoso (Tabelas 1 e 2). Ambos os grupos receberam a mesma ração, portanto, os tratamentos diferiram apenas quanto ao fornecimento da cultura de levedura Saccharomyces cerevisiae cepa 1026 (Beef-Sacc ${ }^{\circledR}$ ), na quantidade de $1 \mathrm{~g} / 100 \mathrm{~kg}$ de peso vivo.

O período experimental teve duração de 22 dias, de modo que os dez primeiros foram destinados à adaptação dos animais às condições experimentais e aos ajustes do consumo voluntário. A partir do 110 dia, o consumo foi restrito a $90 \%$ do consumo voluntário. A ração foi fracionada em quatro refeições da seguinte forma: 30, 15, 15 e 40\% às $6,9,13$ e $16 \mathrm{~h}$, respectivamente. A suplementação com cultura de levedura foi fracionada em duas porções de mesmo peso e colocada via cânula ruminal imediatamente antes da primeira e da quarta refeição do dia.

Para determinar o $\mathrm{pH}$, as concentrações de nitrogênio amoniacal $\left(\mathrm{N}-\mathrm{NH}_{3}\right)$ e ácidos graxos voláteis (acético, propiônico e butírico), coletou-se manualmente líquido 
Tabela 1 - Composição em ingredientes das rações experimentais

\begin{tabular}{lc}
\hline Ingrediente & $(\% \mathrm{MS})$ \\
\hline Silagem de sorgo & 50,00 \\
Casca de soja peletizada & 26,03 \\
Sorgo em grão moído & 22,00 \\
Uréia & 0,97 \\
Núcleo mineraloprotéico 1 & 1,00 \\
\hline $1 \mathrm{P}-41,0 \mathrm{~g} / \mathrm{kg} ; \mathrm{Ca}-55,0 \mathrm{~g} / \mathrm{kg} ; \mathrm{Mg}-18,9 \mathrm{~g} / \mathrm{kg} ; \mathrm{S}-59,5 \mathrm{~g} / \mathrm{kg} ; \mathrm{Zn}$ \\
$3.780,0 \mathrm{mg} / \mathrm{kg} ; \mathrm{Cu}-1.134,0 \mathrm{mg} / \mathrm{kg} ; \mathrm{Mn}-2.667,0 \mathrm{mg} / \mathrm{kg}, \mathrm{Co}-63,0 \mathrm{mg} / \mathrm{kg} ;$ \\
$1-73,0 \mathrm{mg} / \mathrm{k} ; \mathrm{Se}-17,5 \mathrm{mg} / \mathrm{kg} ; \mathrm{F}-400 \mathrm{mg} / \mathrm{kg} ; \mathrm{Cl}-204 \mathrm{~g} / \mathrm{kg} ; \mathrm{Na}-129 \mathrm{~g} / \mathrm{kg} ;$ \\
uréia $-300 \mathrm{~g} / \mathrm{kg}$ (equivalente protéico $840 \mathrm{~g} / \mathrm{kg})$.
\end{tabular}

Tabela 2 - Composição nutricional da silagem de sorgo e da ração experimental

\begin{tabular}{|c|c|c|}
\hline $\begin{array}{l}\text { Composição } \\
\text { bromatológica (\% MS) }\end{array}$ & $\begin{array}{l}\text { Silagem de sorgo } \\
\text { (parte aérea) }\end{array}$ & Ração \\
\hline MS & 36,90 & 49,61 \\
\hline MM & 7,44 & 6,15 \\
\hline MO & 92,56 & 93,85 \\
\hline PB & 7,55 & 15,23 \\
\hline EE & 3,41 & 2,46 \\
\hline FDN & 63,98 & 59,38 \\
\hline FDA & 45,57 & 34,76 \\
\hline Hemicelulose & 18,41 & 24,63 \\
\hline $\mathrm{CT}^{2}$ & 81,60 & 76,15 \\
\hline $\mathrm{CNF}^{3}$ & 17,62 & 16,77 \\
\hline $\mathrm{EM}(\mathrm{MJ} / \mathrm{kg})^{4}$ & $10,17 \mathrm{a}$ & $11,59 b$ \\
\hline $\mathrm{Ca}$ & - & 0,47 \\
\hline $\mathrm{P}$ & - & 0,27 \\
\hline \multicolumn{3}{|c|}{$\begin{array}{l}2 \mathrm{CHOT}=100-(\% \mathrm{~PB}+\% \mathrm{EE}+\% \mathrm{MM}) ; \mathrm{NRC}(2001) . \\
3 \mathrm{CNF}=100-(\% \mathrm{PDN}+\% \mathrm{~PB}+\% \mathrm{EE}+\% \mathrm{MM}) ; \mathrm{NRC}(2001) \\
4 \mathrm{a} \mathrm{EM}(\mathrm{MJ} / \mathrm{kg})=10,09-0,0110 \mathrm{MM}+0,0723 \mathrm{EE}-0,0109 \mathrm{~PB} \text { (De Boeve } \\
\text { et al., 1999). } \\
4 \mathrm{E} \mathrm{EM}(\mathrm{MJ} / \mathrm{kg})=13,88+0,02 \mathrm{EE}-0,0140(0,83 \mathrm{FDA})-0,0173 \mathrm{MM} \text { (De Boeve } \\
\text { et al., 1999). }\end{array}$} \\
\hline
\end{tabular}

ruminal imediatamente antes e 4, 8, 12,16 e 20 horas após a primeira refeição, por meio da cânula ruminal, na região de interface líquido:sólido do ambiente ruminal. As amostras foram filtradas em pano de algodão e a leitura de $\mathrm{pH}$ foi imediatamente feita utilizando-se um potenciômetro digital. Foram obtidas duas alíquotas de $40 \mathrm{~mL}$, uma fixada com $1 \mathrm{~mL}$ de ácido clorídrico (1:1) e outra com $8 \mathrm{~mL}$ de ácido metafosfórico a $25 \%$. As alíquotas foram acondicionadas em recipiente plástico, identificadas e congeladas para posterior determinação da concentração de $\mathrm{N}$-amoniacal e ácidos graxos voláteis, respectivamente. Depois de descongeladas, estimou-se a concentração de $\mathrm{N}-\mathrm{NH}_{3}$ no líquido ruminal pelo sistema micro-Kjeldahl, sem digestão ácida, utilizando-se como base para destilação o hidróxido de potássio (2N), segundo técnica descrita por Fenner (1965), adaptada por Vieira (1980). A concentração dos ácidos graxos voláteis foi determinada por cromatografia gasosa, conforme descrito por Erwin et al. (1961).

Os teores de matéria seca (MS), matéria mineral (MM), proteína bruta $(\mathrm{PB})$, extrato etéreo $(\mathrm{EE})$, fibra em detergente neutro (FDN) e fibra em detergente ácido (FDA) dos ingre- dientes e das rações foram obtidos de acordo com os procedimentos descritos por Silva \& Queiroz (2002).

$\mathrm{O}$ delineamento experimental usado foi o inteiramente casualizado. As análises estatísticas de pH e concentrações ruminais de ácidos graxos voláteis foram baseadas na metodologia descrita por Littell et al. (1998), na qual os dados experimentais são mensurados de forma repetida no tempo. Como proposto por Littell et al. (1996), o tempo foi modelado como uma variável regredida. As comparações entre as médias de tratamentos para a concentração de $\mathrm{N}$-amoniacal no líquido ruminal foram feitas pelo teste de Mann-Whitney.

\section{Resultados e Discussão}

A suplementação com cultura de levedura não influenciou $(\mathrm{P}>0,05)$ o $\mathrm{pH}$ ruminal (Figura 1), entretanto, houve interação significativa $(\mathrm{P}<0,05)$ tempos de amostragem $\times$ tratamentos.

$\mathrm{O} \mathrm{pH}$ foi influenciado $(\mathrm{P}<0,01)$ de forma quadrática pelos tempos de coleta e apresentou valores mínimos de 6,60 e 6,56 às 18 h (12 horas após a primeira refeição e 2 horas após a última) e máximos de 6,86 e 6,99 às 6 h (no momento da primeira refeição) nos grupos com e sem adição de cultura de levedura, respectivamente. Esses valores estão um pouco acima do limite superior da faixa ideal para otimização da digestão da fibra e do crescimento das populações de bactérias celulolíticas, que, segundo Ørskov (1982), foi de 6,5 e 6,8.

Segundo Williams et al. (1991), a elevação do pH ruminal 4 horas após o fornecimento de dieta com $50 \%$ de concentrado e suplementação com cultura de levedura provavelmente é conseqüência da modulação dos picos de lactato e da redução na concentração de ácido lático no líquido ruminal. Como neste experimento não houve variações bruscas de pH, é possível inferir que o efeito de modulação ruminal não foi suficiente para que possíveis diferenças entre os tratamentos fossem detectadas.

Resultados semelhantes foram obtidos por Pereira et al. (2001), que, em novilhos Holandês-Zebu alimentados com dietas à base de cana-de-açúcar recebendo de $11 \%$ a $17 \%$ de concentrado na MS, também não observaram mudanças no $\mathrm{pH}$ do líquido ruminal daqueles sob suplementação com $10 \mathrm{~g}$ de cultura de levedura/animal/dia.

A suplementação com cultura de levedura não influenciou $(\mathrm{P}>0,05)$ as concentrações ruminais molares de acetato, propionato, butirato e AGV totais (Figuras 2 e 3). Entretanto, verificou-se interação significativa tempos de amostragem $\times$ tratamentos para as concentrações molares de acetato $(\mathrm{P}<0,07)$ e propionato $(\mathrm{P}<0,05)$. 


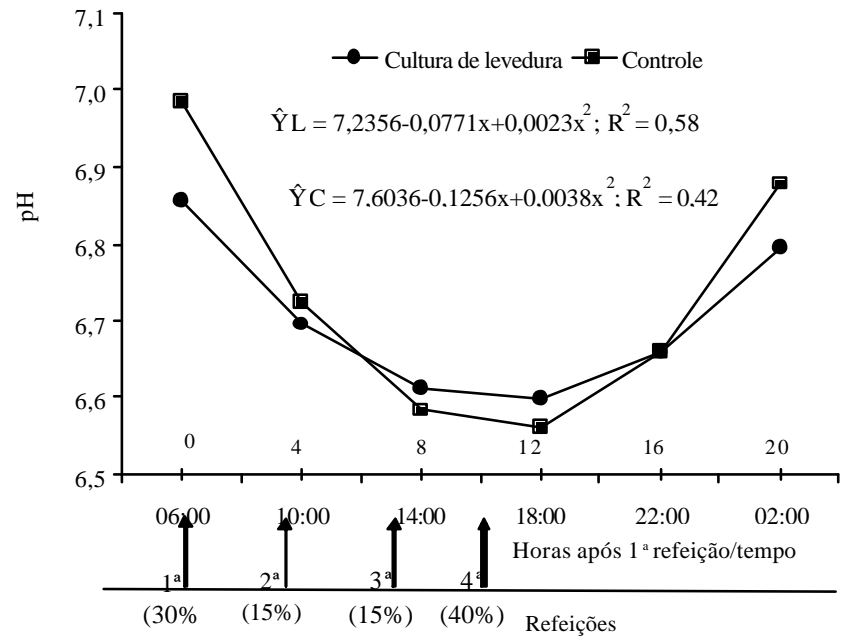

Figura 1 - pH do líquido ruminal nos tempos de coleta nos grupos controle (C) e com suplementação com cultura de levedura $(\mathrm{L})$.

As concentrações ruminais molares de acetato, propionato, butirato e AGV totais foram influenciadas $(\mathrm{P}<0,01)$ de forma quadrática pelos tempos de coleta. A produção dos AGV no rúmen depende da composição e da apresentação física da dieta, assim como do consumo e da freqüência de alimentação (Oliveira, 2005). Neste experimento, o comportamento quadrático das concentrações ruminais molares de acetato, propionato e AGV totais nos tempos de coleta provavelmente esteve relacionado à freqüência alimentar.

Os valores máximos das concentrações ruminais molares de acetato, propionato e AGV totais ajustados nos tempos e horários correspondentes nos grupos com e sem suplementação com cultura de levedura foram, respectivamente, 65,02 vs $60,30 \mu \mathrm{Mol} / \mathrm{mL}$ às 2 e $22 \mathrm{~h} ; 14,66$ vs $11,54 \mu \mathrm{Mol} / \mathrm{mL}$ às 22 e $18 \mathrm{~h}$ e 93,51 vs $88,38 \mu \mathrm{Mol} / \mathrm{mL}$ às 2 e $22 \mathrm{~h}$. No caso do butirato, os valores ajustados em função do tempo nos grupos com e sem suplementação de cultura de levedura foram máximos (12,86 vs $11,28 \mu \mathrm{Mol} / \mathrm{mL})$ às 2 h $(20$ horas após a primeira e 10 horas após a última refeição).

As concentrações médias de acetato $(59,83$ vs 56,30 $\mu \mathrm{Mol} / \mathrm{mL}$ ), propionato (13,18 vs $10,31 \mu \mathrm{Mol} / \mathrm{mL})$ e butirato $(10,48$ vs $10,00 \mu \mathrm{Mol} / \mathrm{mL})$ no líquido ruminal nos grupos com e sem suplementação de cultura de levedura foram levemente inferiores às encontradas por Malcolm \& Kiesling (1990), que, ao fornecerem $40 \%$ de concentrado na dieta de novilhos, não verificaram diferença significativa nas concentrações de acetato e propionato quando forneceram $50 \mathrm{~g}$ de cultura de levedura/animal/dia.

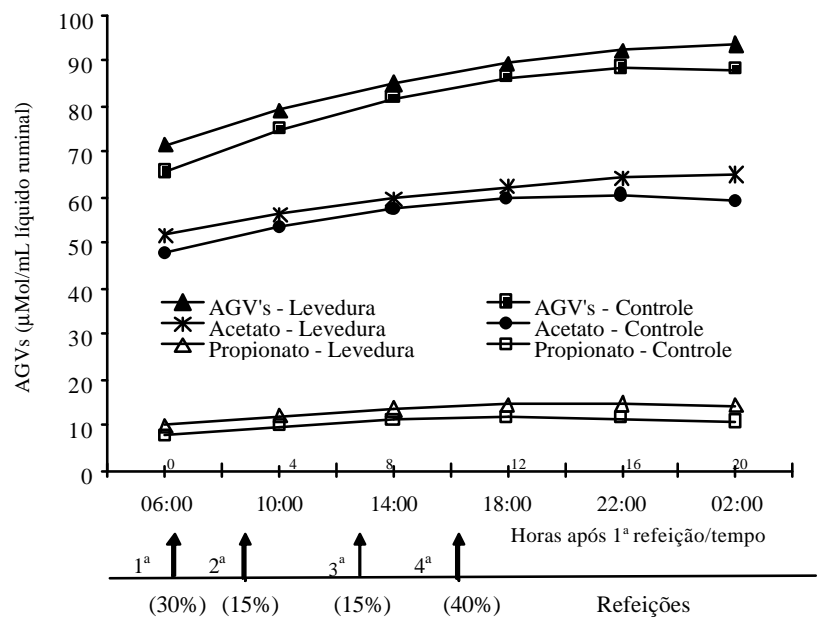

[AGV] Levedura [AGV] Controle

[Acetato] Levedura

[Acetato] Controle

[Propionato] Levedura

[Propionato] Controle

$$
\begin{aligned}
& \hat{Y}=57,3546+2,6538 x-0,0486 x^{2} \\
& \hat{Y}=46,7542+3,5836 x-0,0769 x^{2} \\
& \hat{Y}=43,5836+1,5258 x-0,0270 x^{2} \\
& \hat{Y}=35,955+2,2850 x-0,0536 x^{2} \\
& \hat{Y}=5,5491+0,8619 x-0,0204 x^{2} \\
& \hat{Y}=3,3249+0,8504 x-0,0219 x^{2}
\end{aligned}
$$

Figura 2 - Concentrações molares ruminais de acetato, propionato e ácidos graxos voláteis (AGV) totais nos tempos de coleta nos grupos controle e com suplementação de cultura de levedura.

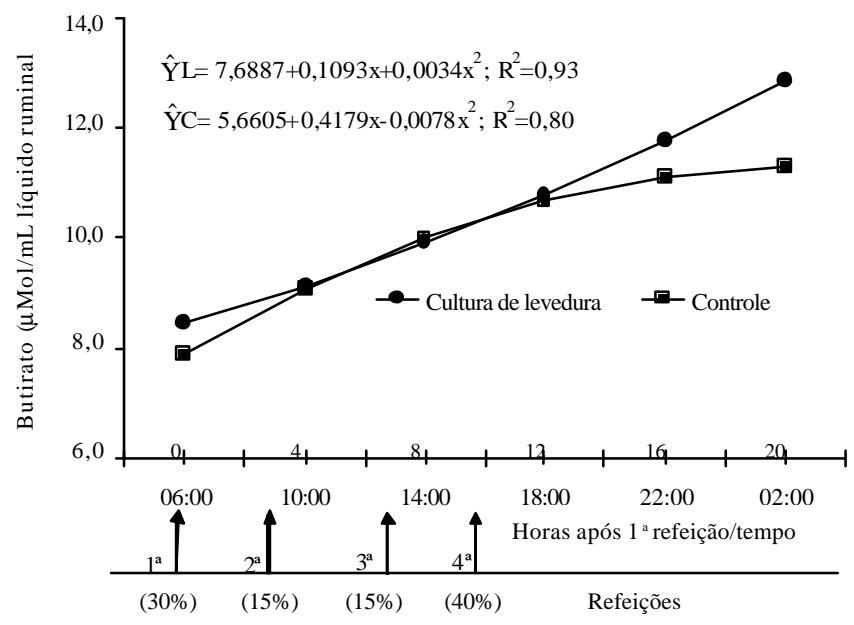

Figura 3 - Estimativa da concentração molar ruminal de butirato nos tempos de coleta nos grupos controle e com suplementação com cultura de levedura.

Neste experimento, as proporções molares médias dos AGV foram aproximadamente $70 \%$ de acetato, $14 \%$ de propionato e $12 \%$ de butirato, valores compatíveis com a dieta estudada ( $50 \%$ de concentrado MS), e corroboram as observações de Miranda et al. (1996), que, ao trabalharem com 27 ou $37 \%$ de FDN (40 ou $60 \%$ de feno de alfafa, respectivamente) e fornecimento de $10 \mathrm{~g}$ de cultura de levedura/animal/dia, obtiveram $72 \%$ de acetato, $16 \%$ de 
propionato e $12 \%$ de butirato e verificaram que a proporção molar de propionato, em ambos os níveis de FDN, aumentou com a adição de cultura de levedura sem que a concentração total de ácidos graxos voláteis fosse alterada.

Resultados favoráveis à adição de cultura de levedura também foram verificados por Mutsvangwa et al. (1992). As concentrações molares ruminais de acetato e de ácidos graxos voláteis totais aumentaram quando bezerros com mais de 3 meses de idade alimentados por 28 semanas com dietas ricas em concentrado receberam suplementação com 8 a $10 \mathrm{~g}$ de cultura de levedura/animal/dia.

A suplementação com cultura de levedura não influenciou $(\mathrm{P}>0,05)$ a relação entre acetato e propionato (Figura 4), pois não houve interação significativa $(\mathrm{P}>0,05)$ tempos de amostragem $\times$ tratamentos para essa relação, que foi influenciada $(\mathrm{P}<0,01)$ quadraticamente pelos tempos de coleta. Para ambos os tratamentos, foram observados valores mínimos de 3,2 às 18 h (12 horas após a primeira refeição e 2 horas após a última) e máximos de 4,1 vs 4,2 às $6 \mathrm{~h}$ (no momento da primeira refeição), para os tratamentos com ou sem adição de cultura de levedura, respectivamente. Esse comportamento quadrático era esperado, uma vez que as concentrações molares ruminais de acetato e propionato também foram influenciadas de forma quadrática pelos tempos de coleta. A média da relação acetato:propionato $(3,51)$ foi superior aos resultados publicados por Williams et al. (1991), que forneceram $10 \mathrm{~g}$ de cultura de levedura/dia a novilhos alimentados com $50 \%$ de volumoso na MS e observaram diminuição da relação acetato:propionato de 3,3 para 2,8 nesses animais, sem que a concentração total de ácidos graxos voláteis fosse alterada.

A concentração ruminal de $\mathrm{N}-\mathrm{NH}_{3}$ às $22 \mathrm{~h}$ (16 horas após a primeira refeição) e 2 h (20 horas após a primeira refeição) foi maior $(\mathrm{P}<0,05)$ quando houve inclusão de cultura de levedura (Tabela 3). Este resultado não era esperado, uma vez que um dos efeitos da adição de levedura na dieta, segundo Newbold et al. (1996), é estimular a atividade e o crescimento das bactérias ruminais, principalmente das celulolíticas, e aumentar a utilização de amônia e a síntese e o fluxo de proteína microbiana para o duodeno. Em muitos trabalhos, a adição de cultura de levedura em dietas ricas em concentrado ou em volumoso não tem influenciado a concentração média de $\mathrm{N}-\mathrm{NH}_{3}$ ruminal (Malcolm \& Kiesling, 1990; Mutsvangwa et al., 1992; Mir \& Mir, 1994; Pereira et al., 2001; Franco et al., 2004).

Entretanto, Miranda et al. (1996), em experimento com novilhas holandesas com peso médio de $300 \mathrm{~kg}$ e alimentadas com rações com 27 ou $37 \%$ de FDN ( 40 ou $60 \%$ de feno de alfafa, respectivamente), observaram que a concentração

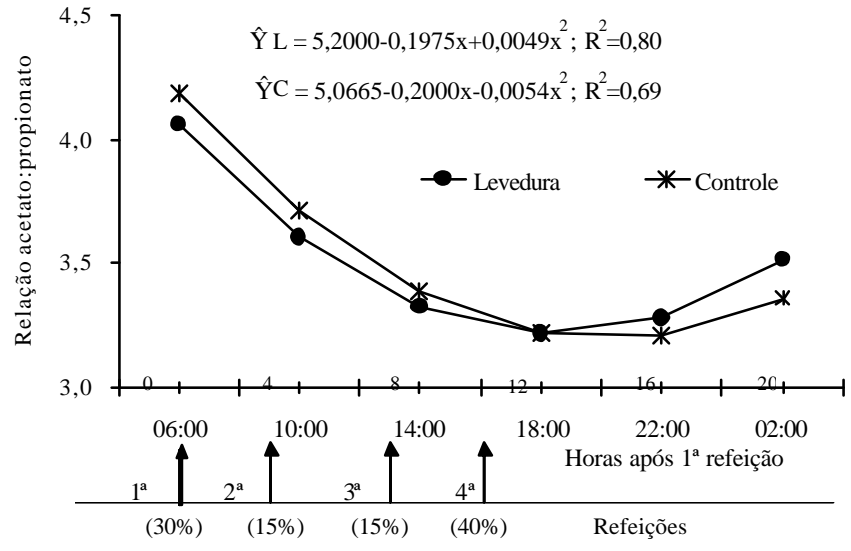

Figura 4 - Relação entre as concentrações molares ruminais de acetato e propionato nos tempos de coleta nos grupos com e sem suplementação com cultura de levedura.

Tabela 3 - Concentração de nitrogênio amoniacal (N-NH3) no líquido ruminal de bovinos suplementados ou não com cultura de levedura

\begin{tabular}{lcrrr}
\hline Horário & $\begin{array}{c}\text { Horas após } \\
\text { 1- refeição }\end{array}$ & \multicolumn{2}{c}{$\begin{array}{c}\text { Concentração ruminal de } \\
\text { N-NH } 3(\mathrm{mg} / 100 \mathrm{~mL})^{1}\end{array}$} & $\mathrm{CV}(\%)$ \\
\cline { 3 - 4 } & & $\begin{array}{c}\text { Cultura de } \\
\text { levedura }\end{array}$ & Controle & \\
\hline $6: 00$ & 0 & $7,90 \mathrm{a}$ & $7,29 \mathrm{a}$ & 14,09 \\
$10: 00$ & 4 & $14,15 \mathrm{a}$ & $13,95 \mathrm{a}$ & 16,72 \\
$14: 00$ & 8 & $9,26 \mathrm{a}$ & $7,19 \mathrm{a}$ & 40,13 \\
$18: 00$ & 12 & $9,18 \mathrm{a}$ & $10,76 \mathrm{a}$ & 25,55 \\
$22: 00$ & 16 & $7,22 \mathrm{a}$ & $5,91 \mathrm{~b}$ & 15,84 \\
$2: 00$ & 20 & $8,99 \mathrm{a}$ & $5,98 \mathrm{~b}$ & 30,97 \\
Média & $9,45 \mathrm{a}$ & $8,51 \mathrm{a}$ & 36,86 & \\
\hline
\end{tabular}

${ }^{1}$ Médias seguidas por letras diferentes na mesma linha diferem $(P<0,05)$ pelo teste Mann-Whitney.

de $\mathrm{N}-\mathrm{NH}_{3}$ três horas após a alimentação foi maior no grupo sob suplementação com $10 \mathrm{~g}$ de cultura de levedura/ animal/dia. Diferentes referenciais são relatados na literatura como níveis críticos para a concentração ruminal de $\mathrm{N}-\mathrm{NH}_{3}$. Leng (1990) afirmou que, em condições tropicais, são necessários mínimos de 10 mg/100 mL e 20 mg/100 mL para maximização da digestão e do consumo de MS, respectivamente.

Os valores obtidos neste estudo para a concentração média de $\mathrm{N}-\mathrm{NH}_{3}$ foram, respectivamente, 9,45 e $8,51 \mathrm{mg} / 100 \mathrm{~mL}$ para os grupos com ou sem adição de cultura de levedura, o que permite inferir que a síntese de proteína microbiana no rúmen não esteve limitada, uma vez que a dieta continha $15,23 \%$ de $\mathrm{PB}$ na MS e que as concentrações ruminais médias de $\mathrm{N}-\mathrm{NH}_{3}$ superaram 6,2 mg/100 mL, nível conside- 
rado por Hoover (1986) como ótimo para o crescimento e a degradação microbiana em bovinos alimentados com dietas com mais de $6 \%$ de $\mathrm{PB}$.

\section{Conclusões}

A suplementação com cultura de levedura $(1 \mathrm{~g} / 100 \mathrm{~kg}$ de peso vivo) não influencia a fermentação ruminal em bovinos de corte quando fornecidas dietas com $50 \%$ de concentrado, com base na matéria seca.

\section{Literatura Citada}

ADAMS, A.L.; HARRIS JR., B.; Van HORN, H.H. et al. Effects of varying forage types on milk production responses to whole cottonseed, tallow, and yeast. Journal of Dairy Science, v.78, n.3, p.573-581, 1995.

DAWSON, K.A.; NEWMAN, K.E.; BOLING, J.A. Effects of microbial supplements containing yeast and lactobacilli on roughage-fed ruminal microbial activities. Journal of Animal Science, v.68, n.10, p.3392-3398, 1990.

DE BOEVER, J.L.; COTTYN, B.G.; DE BRABANDER, D.L. et al. Equations to predict digestibility and energy value of grass silages, maize silages, grass hays, compound feeds and raw materials for cattle. Nutrition Abstracts and Reviews, Series B, v.69, n.11, p.835-850, 1999.

ERWIN, E.S.; MARCO, G.J.; EMERY, E.M. Volatile fatty acid analyses of blood and rumen fluid gas chromatography. Journal of Dairy Science, v.44, n.9, p.1768-1771, 1961.

FRANCO, G.L.; SILVA, F.S.; ROCHA, M.S.T. et al. Efeito da suplementação com levedura e enzimas fibrolíticas sobre os parâmetros ruminais $\mathrm{pH}$ e nitrogênio amoniacal em bovinos alimentados com feno de coast-cross. In: REUNIÃO ANUAL DA SOCIEDADE BRASILEIRA DE ZOOTECNIA, 41., 2004, Campo Grande. Anais... Campo Grande: Sociedade Brasileira de Zootecnia, [2004]. (CD-ROM).

HOOVER, W.H. Chemical factors involved in ruminal fiber digestion. Journal of Dairy Science, v.68, n.10, p.27552766, 1986.

LENG, R.A. Factors affecting the utilization of poor quality forages by ruminants particularly under tropical conditions. Nutrition Research Reviews, v.3, n.1, p.277-303, 1990.

LITTELL, R.C.; HENRY, P.R.; AMMERMAN, C.B. Statistical analysis of repeated measures data using SAS procedures. Journal of Animal Science, v.76, n.4, p.1216-1231, 1998.

LITTELL, R.C.; MILLIKEN, G.A.; STROUP, W.W. et al. SAS ${ }^{\circledR}$ system for mixed models. Cary: SAS Institute, 1996. 633p.

MALCOLM, K.J.; KIESLING, H.E. Effects of whole cottonseed and live yeast culture on ruminal fermentation and fluid passage rate in steers. Journal of Animal Science, v.68, n.7, p.1965$1970,1990$.
MARTIN, S.A.; NISBET, D.J. Symposium: direct-fed microbials and rumen fermentation. Journal of Dairy Science, v.75, n.6, p.1736-1744, 1992 .

MIRANDA, R.L.A.; MENDOZA, M.G.D.; BÁRCENA-GAMA, J.R. et al. Effect of Saccharomyces cerevisae or Aspergillus oryzae cultures and NDF level on parameters of ruminal fermentation. Animal Feed Science Technology, v.63, n.1-4, p.289-296, 1996.

MIR, Z.; MIR, P.S. Effects of the addition if live yeast (Saccharomyces cerevisae) on growth and carcass quality of steers fed high-forage or high-grain diets and on feed digestibility and in situ degradability. Journal of Animal Science, v.72, n.3, p.537-545, 1994.

MUTSVANGWA, T.; EDWARDS, I.E.; TOPPS, J.H. et al. The effect of dietary inclusion of yeast culture (Yea-Sacc) on patterns of rumen fermentation, food intake and growth of intensively fed bulls. Animal Production, v.55, n.1, p.35-40, 1992.

NATIONAL RESEARCH COUNCIL - NRC. Nutrient requirements of dairy cattle. 7.ed. Washington, D.C.: National Academy Press, 2001. 381p.

NEWBOLD, C.J.; WALLACE, R.J.; McINTOSH, F.M. Mode of action of the yeast Saccharomyces cerevisiae as feed additive for ruminants. British Journal of Nutrition, v.76, n.2, p.249$261,1996$.

OLIVEIRA, L.O.F. Estudos de desempenho e consumo, dinâmica ruminal de fase líquida e sólida e digestibilidade in situ co capim Brachiaria brizantha CV. Marandu, em bovinos de corte suplementados com proteinados durante a estação seca do ano. Belo Horizonte, MG: Universidade Federal de Minas Gerais, 2005. 93p. Tese (Doutorado em Ciência Animal) - Universidade Federal de Minas Gerais, 2005.

ØRSKOV, R.O. Protein nutrition in ruminants. London: Academic Press, 1982. 155p.

PEREIRA, E.S.; QUEIROZ, A.C.; PAULINO, M.F. et al. Fontes nitrogenadas e uso de Saccharomyces cerevisiae em dietas à base cana-de-açúcar para novilhos: consumo, digestibilidade, balanço nitrogenado e parâmetros ruminais. Revista Brasileira de Zootecnia, v.30, n.2, p.563-572, 2001.

SILVA, D.J.; QUEIROZ, A.C. Análise de alimentos: métodos químicos e biológicos. 3.ed. Viçosa, MG: Editora UFV, 2002. 253p.

VIEIRA, P.F. Efeito do formaldeído na proteção de proteínas e lipídeos em ração para ruminantes. Viçosa, MG: Universidade Federal de Viçosa, 1980. 98p. Tese (Doutorado em Zootecnia) - Universidade Federal de Viçosa, 1980.

WALLACE, R.J. Ruminal microbiology, biotechnology, and ruminant nutrition: progress and problems. Journal of Animal Science, v.72, n.11, p.2992-3003, 1994.

WALLACE, R. J. The mode of action of yeast culture in modifying rumen fermentatin. In: BIOTECHNOLOGY IN FEED INDUSTRY. Anais... Nottingham: Alltech Inc., University Press, 1996. p.217-232.

WILLIAMS, P.E.V.; TAIT, C.A.G.; INNES, G.M. et al. Effects of the inclusion of yeast culture (Saccharomyces cerevisae plus growth medium) in the diet of dairy cows on milk yield and forage degradation and fermentation patterns in the rumen of steers. Journal of Animal Science, v.69, n.7, p.3016-3026, 1991. 